\title{
Ascorbate metabolism and nitrogen fixation in legumes
}

\author{
Manuel A. Matamoros ${ }^{1}$, David A. Dalton ${ }^{2}$ and Manuel Becana ${ }^{1}$ \\ ${ }^{1}$ Estación Experimental de Aula Dei, CSIC, Apartado 13034, 50080 Zaragoza, Spain \\ ${ }^{2}$ Biology Department, Reed College, Portland, OR 97202, USA
}

*Corresponding Author's e-mail: becana@eead.csic.es

\begin{abstract}
Ascorbic acid (AsA) is a major antioxidant and redox buffer in plants that acts as a direct scavenger of reactive oxygen species (ROS), substrate of ascorbate peroxidase (APX), and cofactor of key enzymes involved in cell wall expansion and hormone biosynthesis. $\mathrm{N}_{2}$-fixing root nodules of legumes contain high levels of AsA (1-2 mM), APX ( $0.9 \%$ of the total soluble protein), and the other enzymes of the AsA-glutathione pathway. The AsA content and their associated enzyme activities are strongly correlated with $\mathrm{N}_{2}$ fixation, providing adequate protection of nodules against ROS generated by, among other processes, the oxidation of nitrogenase and leghemoglobin. These antioxidant defenses are concentrated in the infected zone and in the endodermis/nodule parenchyma, where they may be part of the $\mathrm{O}_{2}$ diffusion barrier that restricts entry of $\mathrm{O}_{2}$ into the nodule interior to avoid nitrogenase inactivation. AsA can enhance $\mathrm{N}_{2}$ fixation four- to five-fold when supplied by stem infusion to soybean plants or when added, along with APX, to an in vitro reconstitution system. GDP-D-mannose 3,5-epimerase (GME) and GDP-L-galactose phosphorylase (GGP) catalyze critical limiting steps in AsA biosynthesis. Consequently, studies are underway to produce transgenic $\mathrm{N}_{2}$-fixing plants that overexpress GME and GGP. Preliminary results have indicated that these plants have higher rates of $\mathrm{N}_{2}$ fixation but with a metabolic cost, resulting in slightly smaller plants. Additionally, since AsA oxidation and decline are early symptoms of nodule aging, a high AsA content might delay nodule senescence and extend the period of $\mathrm{N}_{2}$ fixation.
\end{abstract}

Keywords: Ascorbate biosynthesis, ascorbate peroxidase, leghemoglobin, nitrogen fixation, nodules, oxygen diffusion barrier, symbiosis 


\section{Contents}

Introduction

1 Overall roles of AsA in plants

2 General introduction to biological $\mathrm{N}_{2}$ fixation

3 Production of ROS and RNS in nodules

$4 \quad$ AsA and associated antioxidant enzymes in nodules

5 Benefits of exogenous AsA on $\mathrm{N}_{2}$ fixation

6 Metabolic pathways of AsA biosynthesis in plants and nodules

7 Regulation of AsA biosynthesis during nodule senescence and stress

$8 \quad$ Conclusions

References

\section{Introduction}

All organisms produce reactive oxygen species (ROS), such as superoxide radicals and hydrogen peroxide $\left(\mathrm{H}_{2} \mathrm{O}_{2}\right)$, as well as reactive nitrogen species (RNS), such as nitric oxide (NO) and nitrosothiols. Antioxidants keep the concentrations of ROS and RNS under tight control to allow intracellular redox signaling while preventing nitrooxidative damage of vital cellular components.

Ascorbic acid (AsA) or vitamin $\mathrm{C}$ is a major water-soluble antioxidant and redox buffer in plant and animal cells. At physiological $\mathrm{pH}$, AsA is mostly found (>99.5\%) as ascorbate, the deprotonated form. Humans and some other primates, bats, and guinea pigs cannot synthesize AsA and need to incorporate it in their diet. In humans, diets deficient in AsA cause scurvy, evidenced by gum swelling and severe joint pain, among other symptoms, due to incorrect collagen hydroxylation (Myllylä et al. 1978).

In plants, AsA performs a dual function as antioxidant, by directly scavenging ROS (Buettner and Jurkiewicz 1996) and by being the substrate of ascorbate peroxidase (APX), a critical enzyme of the ascorbate-glutathione or Foyer-Halliwell-Asada 
pathway for $\mathrm{H}_{2} \mathrm{O}_{2}$ detoxification (Foyer and Noctor 2011). This pathway is fully operative in leaves, roots, and nodules (Noctor and Foyer 1998; Dalton et al. 1986). Although the infected region of $\mathrm{N}_{2}$-fixing legume nodules is nearly anaerobic, there is still potential for ROS production by the oxidation of leghemoglobin (Lb), ferredoxin, and nitrogenase, all of them essential proteins for $\mathrm{N}_{2}$ fixation (Becana et al. 2010). Consequently, AsA and the associated antioxidant enzymes are particularly crucial for proper functioning of nodules. Several studies strongly suggest that increasing AsA in nodules can result in increased $\mathrm{N}_{2}$ fixation and delayed senescence. The stage is set for ongoing studies to produce transgenic plants with elevated AsA in hopes of generating plants with enhanced $\mathrm{N}_{2}$ fixation and tolerance of abiotic stresses.

\section{Overall roles of AsA in plants}

The antioxidant actions of AsA stems from its ability to directly scavenge ROS and from its pivotal role in the ascorbate-glutathione pathway. In this pathway four enzymes participate in concert to reduce $\mathrm{H}_{2} \mathrm{O}_{2}$ to water by using, ultimately, NADH and NADPH as electron donors. APX catalyzes the reduction of $\mathrm{H}_{2} \mathrm{O}_{2}$ by AsA, which is oxidized to monodehydroascorbate (MDHA) and dehydroascorbate (DHA). These are reduced back to AsA by NADH-dependent monodehydroascorbate reductase (MDHAR) and glutathione-dependent dehydroascorbate reductase (DHAR). In turn, reduced glutathione is regenerated by NADPH-dependent glutathione reductase. In legumes, homoglutathione ( $\gamma$ Glu-Cys- $\beta$ Ala) may partially or completely replace glutathione ( $\gamma$ Glu-Cys-Gly) as reductant for DHAR (Becana et al. 2010). Besides its antioxidant functions, AsA plays a critical metabolic role as cofactor of numerous enzymes, including violaxanthin de-epoxidase, prolyl-hydroxylase, and dioxygenases involved in photoprotection, cell wall glycoprotein hydroxylation, and in ethylene, gibberellin, and abscisic acid biosynthesis (Arrigoni and De Tullio 2002; Müller-Moulé et al. 2003).

The functions of AsA in plants have been investigated using vitamin $C$ (vtc) mutants of Arabidopsis thaliana that contain only $10-30 \%$ of the AsA levels of wild-type plants (chapter 1). Such experiments have demonstrated that AsA is essential for normal growth and development (Veljovic-Jovanovic et al. 2001; Dowdle et al. 2007). The vtc1 mutants, deficient in GDP-mannose pyrophosphorylase (VTC1/GMP), are more sensitive to ozone (Conklin et al. 1997) and salt stress (Huang et al. 2005). On the other hand, the vtc2 mutants, deficient in GDP-L-galactose phosphorylase (VTC2/GGP), 
show reduced capacity to dissipate as heat the excess of absorbed light energy (MüllerMoulé et al. 2003). The low-AsA mutants also show up-regulation of defense genes and are more resistant to bacterial and fungal pathogens (Pastori et al. 2003; Barth et al. 2004; Pavet et al. 2005). In tomato plants, silencing of the gene encoding the last enzyme of AsA biosynthesis, mitochondrial L-galactono-1,4-lactone dehydrogenase $(\mathrm{GaLDH})$, caused a strong reduction in leaf and fruit size due to diminished cell expansion (Alhagdow et al. 2007).

As could be anticipated, the enzymes that regenerate AsA are also important in the response to abiotic stress. An A. thaliana mutant in cytosolic DHAR showed lower AsA/DHA ratio and exhibited increased ozone sensitivity (Yoshida et al. 2006). Tobacco plants overexpressing MDHAR or DHAR in the cytosol showed higher levels of reduced AsA and enhanced stress tolerance (Eltayeb et al. 2006; 2007). Similarly, tomato seedlings overexpressing chloroplastic MDHAR showed increased resistance to low or high temperatures, whereas antisense transgenic lines were more sensitive to the same stress conditions (Li et al. 2010).

The alterations in growth, development, and stress responses observed in AsA-deficient plants are probably due, at least partially, to modifications in redox dependent signaling pathways. In this regard, several studies suggest that AsA is part of a complex network that modulates hormone signaling (Pastori et al. 2003; Barth et al. 2004; Kerchev et al. 2011). In addition to chloroplasts, AsA has been found in the cytosol, nuclei, peroxisomes, and mitochondria (Jiménez et al. 1997; Zechmann 2011) and it may therefore contribute to the control of $\mathrm{H}_{2} \mathrm{O}_{2}$ concentration and redox state in different cellular sites, thereby influencing cell signaling and gene expression.

\section{General introduction to biological fixation}

Leguminous plants are a major protein source for animal and human nutrition. In addition, crop legumes are able to establish $\mathrm{N}_{2}$-fixing symbioses with soil bacteria (rhizobia) that contribute fixed nitrogen to the soil (Udvardi and Poole 2013). $\mathrm{N}_{2}$ fixation occurs within nodules, a unique organ formed mainly on roots as a result of a complex molecular dialogue between the plant (macrosymbiont) and the bacteria (microsymbiont) (Oldroyd 2013). In nitrogen poor soils, legume roots secrete flavonoids that induce the synthesis of lipochitooligosaccharides known as nodulation (Nod) factors. These interact with specific receptors in the plasma membrane of root 
hair cells triggering a signaling pathway that sequentially involves oscillations in intracellular calcium levels, activation of protein kinases and transcription factors, changes of gene expression, and cell differentiation. The outcome is the formation of a new meristem in the root cortical cells, which are colonized through infection threads. Bacteria are released from the infection threads into single membrane-bound compartments inside the nodule cells, the symbiosomes, where the bacteria differentiate into $\mathrm{N}_{2}$-fixing bacteroids. According to the growth pattern, two types of nodules can be distinguished (Figure 1). For terminology of nodule structure, we will follow Vasse et al. (1990) for indeterminate nodules and Minchin et al. (2008) for determinate nodules.

\section{Insert Figure 1 here}

Indeterminate nodules, such as those of pea (Pisum sativum), clover (Trifolium repens), and the model legume Medicago truncatula, have persistent meristems, show a longitudinal gradient of age, and are usually cylindrical. Generally, four zones can be distinguished from the distal to the proximal (closest to the root) region: I (meristem), II (invasion), III ( $\mathrm{N}_{2}$-fixing), and IV (senescent). In old nodules, an additional zone (V) can be observed adjacent to zone IV which contains undifferentiated bacteria. These nodules have, from exterior to interior, an outer cortex, endodermis, inner cortex (nodule parenchyma) with vascular bundles, and infected zone. Determinate nodules, such as those of bean (Phaseolus vulgaris), soybean (Glycine max), and the model legume Lotus japonicus, do not have persistent meristems or tissues at different developmental stages. They are usually spherical and have a multi-layered cortex and a central infected zone. The cortex of soybean nodules, the best studied, comprises: outer cortex, common endodermis (scleroid layer), mid cortex, and inner cortex (nodule parenchyma). The nodule parenchyma, in turn, is formed by a boundary layer with no apparent intercellular spaces and a distribution zone with small cells and large intercellular spaces. The two types of nodules also differ in biochemical terms (for details on the structure and function of both types of nodules, see Minchin et al. 2008 and Dupont et al. 2012; Figure 1). For example, indeterminate nodules produce amides (glutamine and asparagine) as nitrogen compounds that are exported to the shoot, whereas determinate nodules produce ureides (allantoin and allantoic acid). There are exceptions to this as L. japonicus is an amide exporter. 
The plant provides photosynthates to the nodules, mostly sucrose, through the phloem. In the cytoplasm of host cells, sucrose is oxidized to malate and other dicarboxylic acids which are then used up by the bacteroids to sustain $\mathrm{N}_{2}$ fixation (Udvardi and Poole 2013). This process is catalyzed by a complex of two enzymes, dinitrogenase reductase and dinitrogenase, that fixes $\mathrm{N}_{2}$ into ammonia. The reaction requires large amounts of ATP and reducing power as well as nearly anaerobic conditions because the enzymes are irreversibly inactivated by $\mathrm{O}_{2}$. Consequently, mechanisms exist in nodules that strictly control $\mathrm{O}_{2}$ concentration so as to allow high rates of bacteroid respiration while avoiding oxidation of nitrogenase components. Two major $\mathrm{O}_{2}$ regulating mechanisms are $\mathrm{Lb}$, a monomeric hemeprotein similar to animal myoglobin that transports $\mathrm{O}_{2}$ at a steady but low concentration in the cytosol of infected cells (Appleby 1984), and an $\mathrm{O}_{2}$ diffusion barrier (ODB) localized in the nodule parenchyma which limits the flux of $\mathrm{O}_{2}$ into the infected zone (Witty et al. 1986). The resulting ammonia is released into the infected cell cytosol, assimilated into carbon compounds by glutamine synthetase and glutamate synthase, and exported to the shoot in the form of amides or ureides. Thus, in simple terms, the legume-rhizobia symbiosis consists of an exchange of carbon and nitrogen between the plant and the bacteria.

\section{Production of ROS and RNS in nodules}

In plant cells, respiration, photosynthesis and other metabolic reactions involving electron transfer may generate ROS such as superoxide radicals and $\mathrm{H}_{2} \mathrm{O}_{2}$. Two additional, more powerful oxidizing ROS are the hydroxyl radicals and singlet oxygen, which can originate through the Fe-catalyzed Fenton reaction and energy transfer reactions, respectively (Halliwell 2006). Both ROS can readily react with lipids, proteins, and DNA causing extensive damage to membranes and other cellular components. Under physiological conditions, ROS are maintained at low steady-state concentrations by antioxidant enzymes and metabolites, allowing them to perform signaling functions (Choudhury et al. 2017). In contrast, under adverse conditions and during senescence, the balance between ROS production and antioxidant defenses may be lost, leading to alterations in redox homeostasis, oxidation of cellular components, and, ultimately, plant death. This situation is known as oxidative stress and is manifested by the accumulation of lipid peroxides, carbonylated proteins, and oxidized DNA bases (Pisoschi and Pop 2015). Similarly, RNS such as NO carry out multiple 
functions in plants, including stress perception and signaling, but the uncontrolled production of NO and NO-derived RNS like peroxynitrite leads to nitrosative stress, characterized by indiscriminate nitrosylation and nitration of proteins and other molecules. Thus, the frontier between oxidative/nitrosative signaling (beneficial situation) and oxidative/nitrosative stress (detrimental situation) seems to be a tenuous one.

The establishment of the legume-rhizobia symbiosis and nodule functioning require finely-tuned concentrations of ROS and RNS. Transient increases in both types of reactive molecules have been detected within minutes or hours after preception of Nod factors by the plant at the very early stage of symbiosis (Puppo et al. 2013). Also, superoxide and $\mathrm{H}_{2} \mathrm{O}_{2}$ have been detected within the infection threads and infected cells of nodules (Santos et al. 2001; Alesandrini et al. 2003; Rubio et al. 2004). Superoxide can be produced by membrane-localized NADPH oxidases (Marino et al. 2011; Arthikala et al. 2014), the autoxidation of oxygenated Lb, and the electron transport chains of bacteroids and mitochondria. Superoxide radicals can then dismutate to $\mathrm{H}_{2} \mathrm{O}_{2}$ either spontaneously or through a reaction catalyzed by superoxide dismutases.

Likewise, RNS, and especially NO, may arise from different sources. In the nodule host cells, these include a NO synthase-like protein (Cueto et al. 1996) and nitrate reductase activity in combination with the mitochondrial electron transport chain under hypoxic conditions (Horchani et al. 2011). In the bacteroids, NO is formed in the denitrification pathway (Meakin et al. 2007; Sánchez et al. 2010; Horchani et al. 2011) and perhaps also through a bacterial NO synthase-like activity (Meilhoc et al. 2011).

\section{AsA and associated antioxidant enzymes in nodules}

Dalton et al. (1986) were the first to report in legume nodules the presence of the AsAglutathione pathway, as well as high concentrations of AsA (1-2 mM) and APX $(0.9 \%$ of the total soluble protein). Depending on the legume species, this AsA concentration is $15-40 \%$ of that observed in the leaves and slightly greater than that in the roots (Matamoros et al. 2006). However, AsA is not uniformly distributed within the nodule. In fact, antioxidant concentrations are expected to be higher in regions prone to ROS production. In nodules such conditions are found in the infected cells and in some peripheral cell layers in the cortex. In determinate nodules, the presence of an ODB in the nodule parenchyma physically restricts movement of $\mathrm{O}_{2}$ into the interior such that 
the infected zone becomes nearly anaerobic. The anaerobic status is further enforced by elevated rates of respiratory $\mathrm{O}_{2}$ consumption in the endodermis (indeterminate nodules) or parenchyma (determinate nodules), and indeed we have proposed that this may be an additional mechanism for restricting $\mathrm{O}_{2}$ access to the central zone (Dalton et al. 1998). Histochemical stains and/or immunolocalization studies revealed that these regions have elevated respiratory dehydrogenase activity (Figure 2) and high concentrations of AsA (Figure 3A, B) and APX (Figure 3C, D). Abundant antioxidants were also located in the infected zone even though the microenvironment here is nearly anaerobic. The central zone of nodules does not only contain infected cells repleted of bacteroids but also uninfected (interstitial) cells. If the premise that antioxidants are critical to support $\mathrm{N}_{2}$ fixation is correct, one would expect greater antioxidant levels in infected than in uninfected cells. This appears to be the case at least for APX mRNA for which in situ hybridization showed more intense labeling in the infected cells (Figure 4). As occurs for AsA and APX, the (homo)glutathione concentration is also enhanced in the nodule parenchyma (Figure 5), strongly suggesting that the AsA-glutathione pathway is very active in this nodule region and that it may be involved in the operation of the ODB. This would be in keeping with an early proposal that $\mathrm{H}_{2} \mathrm{O}_{2}$, whose concentration is controlled by the pathway, acts as a signal in the ODB (Minchin 1997).

\section{Insert Figures 2 and 3 here}

The evidence from microscopy is supported by careful microdissection of nodules into cortical and infected tissue. This technique does not permit a fine-enough distinction between discrete cell layers such as endodermis and parenchyma but it does provide a clear separation between peripheral versus central infected tissue. Concentrations of AsA and (homo)glutathione were $\sim 44 \%$ higher in the peripheral layers of bean nodules (Dalton et al. 1998). The concentration of AsA in the periphery was estimated to be $\sim 1-$ $1.5 \mathrm{mM}$ and that of (homo)glutathione $\sim 0.5 \mathrm{mM}$. The microdissection studies also allowed a comparison of enzyme specific activities in different regions of nodules. APX was not significantly different between periphery and infected regions, a misleading fact presumably brought about by the dilution of peripheral extracts with layers in the nodule cortex that are depleted in this enzyme. Even so, extracts from the periphery of bean nodules contained 57\%, 77\%, and 27\% more MDHAR, DHAR, and glutathione reductase activities, respectively, than those present in the infected zone (Dalton et al. 
1998). These authors proposed that elevated respiration rates in the endodermis and parenchyma contribute to the restriction of $\mathrm{O}_{2}$-difussion into the infected zone, thus protecting nitrogenase from inactivation. High levels of AsA and AsA-glutathione pathway enyzmes at the ODB might contribute to keep respiration-derived ROS at low concentrations. It is also relevant that ascorbate oxidase (AO), an enzyme that catalyzes the oxidation of AsA to DHA using $\mathrm{O}_{2}$, is induced in nodules and mycorrhizal roots of L. japonicus (Balestrini et al. 2012). Notably, the AO mRNA and protein were found to be highly expressed in the intercellular spaces of the nodule parenchyma. These authors proposed that AO could participate in the ODB by directly scavenging $\mathrm{O}_{2}$ without the production of intermediate ROS. Taken all these observations together, it is clear that the nodule parenchyma is closely linked to AsA and its associated enzymes.

\section{Insert Figures 4 and 5 here}

The peripheral location of antioxidants was confirmed in a study that used fusion of the GUS reporter gene with the promoters for glutathione synthetase and homoglutathione synthetase genes from M. truncatula (El Msehli et al. 2011). GUS expression from both reporter constructs was mainly observed in the vascular tissue and the cortex of nodules. Thus, (homo)glutathione appears to be concentrated in the same region of the nodule as AsA and APX. Interestingly, the expression of $\gamma$-glutamylcysteine synthetase ( $\gamma$ ECS), which is the key regulatory enzyme in the (homo)glutathione biosynthetic pathway, was greater in the meristem area and adjacent developing infection zone.

The hypothesis that symbiotic $\mathrm{N}_{2}$ fixation depends on antioxidants such as AsA and (homo)glutathione was strengthened by the observation that nodule effectiveness (the rate of $\mathrm{N}_{2}$ fixation) is correlated with the concentration of antioxidants in nodules (Dalton et al. 1993). In this case, nodules from six effective legume-rhizobia pairings were compared with nodules from six ineffective pairings. All enzymes of the AsAglutathione pathway were much elevated in the effective pairings, by as much as 5.5fold in the case of glutathione reductase. In addition, levels of (homo)glutathione were 4.3-fold higher in effective nodules and the ratio of reduced to oxidized (homo)glutathione was 2.9-fold higher in effective nodules. However, no differences in AsA concentration were detected between the pairings.

Varying the concentration of free $\mathrm{O}_{2}$ surrounding nodules has been reported to have significant effects on antioxidant defenses (Dalton et al. 1991). Higher concentrations of 
$\mathrm{O}_{2}$ resulted in increases in the activity of the enzymes of the AsA-(homo)gluatathione pathway as well as concentrations of AsA and (homo)glutathione. There was also a correlation with higher concentrations of $\mathrm{O}_{2}$ leading to increased rates of $\mathrm{N}_{2}$ fixation (acetylene reduction). These observations support the hypothesis that the supply of $\mathrm{O}_{2}$ may be limiting to $\mathrm{N}_{2}$ fixation.

The correlation between antioxidants and $\mathrm{N}_{2}$ fixation was further confirmed in a study involving $\gamma$ ECS (El Msehli et al. 2011). Down-regulation of the $\gamma E C S$ gene by RNAi led to decreases in $\mathrm{N}_{2}$ fixation as well as in levels of $\mathrm{Lb}$, thiols, and thioredoxin (a protein that acts as an antioxidant by facilitating the reduction of other proteins). Overexpression of the $\gamma E C S$ gene led to higher contents of (homo)glutathione, Lb, sucrose synthase, and thioredoxin, as well as higher rates of $\mathrm{N}_{2}$ fixation.

\section{Benefits of exogenous AsA on $\mathrm{N}_{2}$ fixation}

There are several studies that provide evidence for a direct link between AsA and $\mathrm{N}_{2}$ fixation in legumes. For instance, foliar application of AsA led to a wide range of beneficial responses in $\mathrm{N}_{2}$-fixing rhizobia-legume symbioses, including accelerated nodule formation and increases in nodule number (up to 10-fold), nodule weight, AsA and $\mathrm{Lb}$, as well as in the nitrogen content of nodules and other plant organs including leaves (Chinoy 1984). Also, the supply of AsA to plants increased yield up to 6-fold and delayed nodule senescence. The application of exogenous AsA through root feeding of soybeans led to increases in root and nodule mass, number of nodules, accelerated nodule development, and nitrogenase and APX activities (Bashor and Dalton 1999).

In contrast to these favorable responses to exogenous AsA, a similar treatment was found to have no benefit in the response of $\mathrm{N}_{2}$-fixing pea nodules to water stress (Zabalza et al. 2008). The application of exogenous AsA did not produce recovery from water stress as measured by nodule antioxidant enzymes, nodule carbon and nitrogen enzymes, or $\mathrm{N}_{2}$ fixation. One reason for the lack of response may be that the AsA concentration $(5 \mathrm{mM})$ used in this study may have been below the level necessary to provide benefits. In stem infusion treatments, effects were only observed with $10 \mathrm{mM}$ AsA. Furthermore, the application of AsA to water-stressed plants paradoxically led to much lower foliar concentrations of AsA and glutathione compared to levels in control plants (Zabalza et al. 2008). Consequently, favorable responses to AsA-treatment would not be expected. 
Even more profound effects were observed when AsA was provided to plants by stem infusion of a buffered solution of AsA. In this case, AsA led to increases of nitrogenase and APX activities and Lb content (Figure 6) and to decreases of lipid peroxide levels (Bashor and Dalton 1999). Additional benefits included delayed senescence in which Lb content and nitrogenase activity were maintained through late developmental stages while both factors declined in control plants. This is consistent with the role of AsA in nodule senescence as discussed below.

\section{Insert Figure 6 here}

Because $\mathrm{N}_{2}$ fixation and other parameters of nodule function are enhanced by treatment with AsA, it is reasonable to suggest that antioxidants may be a limiting factor in $\mathrm{N}_{2}$ fixation. Such conclusions are linked to the hypothesis that $\mathrm{O}_{2}$ itself might be the most limiting factor for $\mathrm{N}_{2}$ fixation (Witty et al. 1986; Hunt and Layzell 1993). $\mathrm{O}_{2}$ might be limiting because a higher $\mathrm{O}_{2}$ concentration would require enhanced antioxidants to deal with the increased production of ROS. These complementary hypotheses have implications towards improving $\mathrm{N}_{2}$ fixation through genetic engineering as discussed later. In particular, enhanced antioxidants may facilitate or enable the entry of more $\mathrm{O}_{2}$ into the nodule interior to support bacteroid respiration and thus higher rates of $\mathrm{N}_{2}$ fixation.

AsA has also been shown to be highly beneficial to $\mathrm{N}_{2}$ fixation in an in vitro reconstitution system (Ross et al. 1999). This system consisted of sealed vials containing the essential components of an intact nodule, namely: $\mathrm{N}_{2}$-fixing rhizobia, $\mathrm{Lb}$ (or myoglobin), purified recombinant APX, and various concentrations of AsA (up to 2 $\mathrm{mM}$ ) with a gas head space consisting of $3 \% \mathrm{O}_{2}$. The goal was to create a functional $\mathrm{N}_{2}$ fixing system in which $\mathrm{Lb}$ or myoglobin supplies $\mathrm{O}_{2}$ to meet the respiratory demands of the rhizobia. Just as in nodules, the system would be damaged by $\mathrm{H}_{2} \mathrm{O}_{2}$ produced by the autoxidation of $\mathrm{Lb}$ or myoglobin, hence the need for APX and AsA. Profound benefits were observed when AsA was provided at the highest concentration. These benefits included increased fractional oxygenation of myoglobin indicating that myoglobin remains in the ferrous form and binds $\mathrm{O}_{2}$. Over the time course of the experiment $(9 \mathrm{~h})$ there was a $40 \%$ decline in the fractional oxygenation of myoglobin in the absence of AsA. In the presence of AsA the myoglobin remained fully oxygenated. The inclusion of AsA and APX also resulted in a 4.5-fold increase in nitrogenase activity (acetylene 
reduction). Nitrogenase activity remained linear for $9 \mathrm{~h}$ whereas nitrogenase activity in the absence of AsA and APX was consistently lower and ceased after $6 \mathrm{~h}$.

\section{Metabolic pathways for AsA biosynthesis in plants and nodules}

AsA in plants is synthesized primarily by the L-galactose (or Wheeler-Smirnoff) pathway (Wheeler et al. 1998) of which the two main regulatory steps are the conversion of GDP-L-galactose to L-galactose-1-P by GGP and the conversion of GDPD-mannose to GDP-L-galactose by GDP-mannose 3,5-epimerase (GME). Both enzymes are regulated transcriptionally and GGP also at the translational level (Bulley and Laing 2016). Overexpression of the GGP gene leads to an increase of AsA concentrations up to 16-fold in diverse plant species, and co-overexpression of GGP and GME appears to further increase AsA at least in A. thaliana (Bulley and Laing 2016). These and other observations indicate that the route through L-galactose is the major pathway of AsA biosynthesis in plants.

Regarding the rhizobia-legume symbiosis, the high concentration of AsA found in nodules was initially attributed to import from the leaves through the phloem (Groten et al. 2005; Puppo et al. 2005) and proposed to modulate the content of cytosolic peroxiredoxin, a key antioxidant enzyme for $\mathrm{H}_{2} \mathrm{O}_{2}$ detoxification (Groten et al. 2006). Indeed, the long-distance transport of AsA from the shoot is a plausible possibility and might account for a fraction of the AsA in nodules. However, many data indicate that nodules possess the necessary biochemical machinery to synthesize AsA from glucose through the L-galactose pathway. A gene coding for GalLDH was cloned and characterized in the model legume L. japonicus. The gene codes for a functional protein that is located to the inner membrane of nodule mitochondria and that is expressed in leaves and nodules at similar levels (Matamoros et al. 2006). Moreover, GalLDH mRNA was localized by in situ hybridization in the infected zone of alfalfa and $L$. japonicus nodules, and high GalLDH activity was detected in the infected zone of alfalfa and bean nodules (Matamoros et al. 2006). Subsequently, genes encoding GMP, GME, L-galactose-1-P phosphatase (GalPP), and L-galactose dehydrogenase (GalDH) were found to be expressed in nodules (Loscos et al. 2008). Although GMP and GME participate in the synthesis of GDP-L-galactose, a common precursor of AsA and cell wall polysaccharides, the enzymes GalPP, GalDH, and GalLDH catalyze the three last steps of the L-galactose pathway (Wheeler et al. 1998). In addition, proteomic studies in 
L. japonicus nodules identified several enzymes involved in AsA metabolism, including phosphomannomutase, GME, and GalPP (Dam et al. 2014). Table I shows the AsA biosynthetic pathway highlighting the transcripts and enzymes identified in nodules. Very recently, proteomic studies have detected the key regulatory enzyme, GGP, in bean nodules (Matamoros et al. 2017), further supporting the presence of a complete biosynthetic pathway in these plant organs.

\section{Insert Table I here}

Studies are underway to produce transgenic $\mathrm{N}_{2}$-fixing plants with elevated AsA content through overexpression of GGP and GME. Preliminary studies in one of our labs (Torres-Jerez et al. 2017) have revealed that GGP-overexpressing plants of $M$. truncatula do indeed have higher rates of $\mathrm{N}_{2}$ fixation, as do plants that overexpress GME. These results were obtained using the constitutive $35 \mathrm{~S}$ promoter from cauliflower mosaic virus. Additional studies are planned using the strong nodule-specific promoter for $\mathrm{Lb}$. The practical implications of this work could be striking since even a small increase in nitrogen fixed or yield could translate to huge agronomic benefits.

Likewise, given the profound, positive responses to stem infusion of AsA, specifically the 4- to 5-fold increase in nitrogenase activity, it is reasonable to expect that increased production of endogenous AsA should lead to increased nitrogenase activity and delayed nodule senescence. Elevated levels of AsA should also confer increased tolerance of stresses such as drought or salinity, probably because of the exacerbated production of ROS under stressful conditions (Miller et al. 2010). Exogenous AsA has been reported to increase tolerance of salinity for tomato seedlings (Shalata and Neumann 2001). Similarly, maize seeds soaked in AsA resulted in seedlings with greater tolerance to salinity (Rady and Hemida 2016). On the contrary, a lower AsA level such as that found in the vtcl mutants of $A$. thaliana caused accumulation of $\mathrm{H}_{2} \mathrm{O}_{2}$ and decreases in activities of the AsA-glutathione enzymes, chlorophyll content, $\mathrm{CO}_{2}$ assimilation, and photosystem II activity (Huang et al. 2005).

Alternative pathways for AsA biosynthesis through myo-inositol (Lorence et al. 2004) or D-galacturonic acid (Valpuesta and Botella 2004) have been proposed in several species. For example, in strawberry fruits, AsA biosynthesis occurs through Dgalacturonic acid, a component of cell wall pectins, and overexpression of Dgalacturonic acid reductase increases AsA concentration (Agius et al. 2003). However, 
the contribution of these pathways to AsA biosynthesis in nodules has not been investigated so far.

\section{Regulation of AsA biosynthesis in nodules during senescence and stress}

Natural senescence or aging is a complex and tightly regulated process entailing the loss of redox homeostasis and the degradation of organelles and macromolecules (Lim et al. 2007). Environmental constraints affect regulation of AsA biosynthesis that may occur through transcriptional and translational control of the L-galactose pathway (Bulley and Laing 2016). In nodules, aging is associated with an almost complete transcriptional inhibition of some genes involved in AsA biosynthesis, a strong decline of GalLDH activity, and consistent decreases in AsA and glutathione (Groten et al. 2005; Loscos et al. 2008). These observations indicate a progressive switch-off of the AsA biosynthetic pathway during nodule aging. Moreover, the capacity for AsA regeneration from MDHA and DHA is also negatively affected. In senescent bean nodules that capacity declines faster in the mitochondria than in the cytosol, which could lead to alterations in the mitochondrial redox state (Matamoros et al. 2013).

In nodules, senescence induced by drought, nitrate, or prolonged darkness shares some features with aging, including inhibition of nitrogenase, degradation of $\mathrm{Lb}$, and decrease of antioxidant redox buffering capacity (Puppo et al. 2005; Becana et al. 2010 and references therein). The concentration of AsA declined by $58-67 \%$ with drought stress in pea and alfalfa nodules (Gogorcena et al. 1995; Naya et al. 2007). However, AsA decreased by $41 \%$ in pea nodules after supply with excess nitrate (Escuredo et al. 1996) but remained constant in common bean nodules under similar conditions (Matamoros et al. 1999). Likewise, drastic declines of AsA were observed with advancing age of pea nodules (Groten et al. 2005; 2006) but not of soybean nodules (Dalton et al. 1986). Therefore, there are species-specific differences in AsA metabolism and/or transport in response to, at least, natural and nitrate-induced nodule senescence. The decline in AsA concentration was accompanied in many cases by corresponding decreases in APX, MDHAR, and DHAR activities in nodules and by increases in oxidative damage of lipids and proteins (Escuredo et al. 1996; Matamoros et al. 1999; Hernández-Jiménez et al. 2002). This suggests that the function of the AsA-glutathione pathway becomes somewhat limited during senescence and that the resulting uncontrolled ROS production may contribute to the inhibition of $\mathrm{N}_{2}$ fixation. The mechanisms for this 
inhibition, however, probably vary with the symbioses and with the type, intensity, and duration of stress.

The regulation of AsA biosynthesis in nodules is poorly known (Table I). GalLDH activity is posttranscriptionally regulated but is not a major determinant for AsA content in nodules under stress conditions (Loscos et al. 2008). Nodules exposed to cadmium, a toxic heavy metal, showed reduced expression of GMP, GME, GalDH, and GalLDH, whereas high salinity had no effect on their expression. This indicates specific transcriptional regulation of AsA biosynthesis in response to various stresses (Table I). Additional regulatory mechanisms might exist. For example, a glycated form of GMP has been very recently identified in bean nodules (Matamoros et al. 2017). Protein glycation is a post-translational modification originated by the reaction of arginine and lysine residues with reducing sugars or $\alpha$-carbonyls derived from them (Bilova et al. 2017). However, information on this modification in plants is virtually nonexistent. There are also evidences of other post-translational modifications (Table I). Thus, phosphorylated and acetylated peptides from enzymes of AsA biosynthesis have been recently detected as a result of an in-depth proteome analysis of several $M$. truncatula organs (Marx et al. 2016). These data revealed that GME can be acetylated and phosphorylated and that GMP can be phosphorylated, suggesting that both types of modifications may play regulatory roles of the enzyme activities.

The regulation of AsA metabolism is also influenced through hormonal crosstalk. Jasmonates (JA) are important regulators of plant development and stress responses (Wasternack and Hause 2013) and induce genes of biosynthesis of glutathione (Xiang and Oliver 1998) and AsA (Wolucka et al. 2005; Loscos et al. 2008). In bean nodules, JA increased GalLDH expression, inhibited DHAR activity at the post-translational level, and increased AO mRNA and activity (Loscos et al. 2008). The two last effects combined may trigger a rapid change in the apoplastic redox state due to AsA oxidation, which in turn might influence the capacity of the apoplast to generate and propagate redox signals.

\section{Conclusions}

AsA is abundant in nodules and plays a critical role in supporting $\mathrm{N}_{2}$ fixation by minimizing damage from ROS. AsA concentration in nodules and other plant organs depends on the rates of biosynthesis, degradation, and transport. Moreover, the ratio 
between the reduced (AsA) and oxidized (MDHA and DHA) forms may influence signaling networks. Research from different laboratories is starting to elucidate the numerous factors and complex regulatory mechanisms that determine AsA homeostasis in plant cells. However, the information on AsA metabolism and regulation in legume nodules is scant and further research is necessary to fill in this gap. In this regard, the generation of legumes with altered AsA concentrations constitutes an excellent tool to investigate the role of this important antioxidant, redox buffer, and signaling metabolite. These plants may help shed light on the mechanisms by which AsA increases $\mathrm{N}_{2}$ fixation. Thus, from an agronomical viewpoint, enhanced AsA levels might improve the stress tolerance and yield of crop legumes. Another major feature of AsA in nodules is its potential contribution to the operation of the ODB. The enhanced levels of AsA, APX, and (homo)glutathione along with a high respiratory activity in the nodule parenchyma provide strong support for the involvement of the mitochondrial respiration and AsA-glutathione pathway in the ODB, probably entailing rapid fluctuations in $\mathrm{H}_{2} \mathrm{O}_{2}$ concentration. Extensive physiological, biochemical, and cellular studies with transgenic plants are anticipated to be invaluable to test this appealing hypothesis.

\section{Acknowledgments}

Work from our laboratories described in this review article was funded by grants AGL2011-24524 and AGL2014-53717-R from the Ministry of Economy and Competitiveness-Fondo Europeo de Desarrollo Regional to M.B. and by grants DCB8903254, IBN-9206453, IBN-9507491, and IOS-0517688 from the National Science Foundation to D.A.D.

\section{References}

Agius F, González-Lamothe R, Caballero JL, Muñoz-Blanco J, Botella MA, Valpuesta V (2003) Engineering increased vitamin C levels in plants by overexpression of a Dgalacturonic acid reductase. Nature Biotech 21: 177-181

Alesandrini F, Mathis R, Van de Sype G, Hérourart D, Puppo A (2003) Possible roles for a cysteine protease and hydrogen peroxide in soybean nodule development and senescence. 158: 131-138

Alhagdow M, Mounet F, Gilbert L, Nunes-Nesi A, Garcia V, Just D, Petit J, Beauvoit B, Fernie AR, Rothan C, Baldet P (2007) Silencing of the mitochondrial ascorbate 
synthesizing enzyme L-galactono-1,4-lactone dehydrogenase affects plant and fruit development in tomato. Plant Physiol 145: 1408-1422

Appleby CA (1984) Leghemoglobins and Rhizobium respiration. Annu Rev Plant Physiol 35: 443-478

Arrigoni O, De Tullio MC (2002) Ascorbic acid: much more than just an antioxidant. Biochim Biophys Acta 1569: 1-9

Arthikala MK, Sánchez-López R, Nava N, Santana O, Cárdenas L. Quinto C (2014) RbohB, a Phaseolus vulgaris NADPH oxidase gene, enhances symbiosome number, bacteroid size, and nitrogen fixation in nodules and impairs mycorrhizal colonization. New Phytol 202: 886-900

Balestrini R, Ott T, Güther M, Bonfante P, Udvardi MK, De Tullio MC (2012) Ascorbate oxidase: the unexpected involvement of a 'wasteful enzyme' in the symbioses with nitrogen-fixing bacteria and arbuscular mycorrhizal fungi. Plant Physiol Biochem 59: 71-79

Barth C, Moeder W, Klessig DF, Conklin PL (2004) The timing of senescence and response to pathogens is altered in the ascorbate-deficient Arabidopsis mutant vitamin C-1. Plant Physiol 134: 1784-1792

Bashor CJ, Dalton DA (1999) Effects of exogenous application and stem infusion of ascorbate on soybean (Glycine max) root nodules. New Phytol 142: 19-26

Becana M, Matamoros MA, Udvardi M, Dalton DA (2010) Recent insights into antioxidant defenses of legume root nodules. New Phytol 188: 960-976

Bilova T, Paudel G, Shilyaev N, Schmidt R, Brauch D, Tarakhovskaya E, Milrud S, Smolikova G, Tissier A, Vogt T, Sinz A, Brandt W, Birkemeyer C, Wessjohann LA, Frolov A (2017) Global proteomic analysis of advanced glycation end products in the Arabidopsis proteome provides evidence for age-related glycation hotspots. J Biol Chem (in press) doi: 10.1074/jbc.M117.794537

Buettner GR, Jurkiewicz BA (1996) Chemistry and biochemistry of ascorbic acid. In Handbook of Antioxidants (E Cadenas, L Packer, eds), pp 91-115. Dekker, New York

Bulley S, Laing W (2016) The regulation of ascorbate biosynthesis. Curr Opin Plant Biol 33: 15-22

Chinoy JJ (1984) The Role of Ascorbic Acid in Growth, Differentiation and Metabolism of Plants. Martinus Nijhoff/Dr W Junk, The Hague 
Choudhury FK, Rivero RM, Blumwald E, Mittler R (2017) Reactive oxygen species, abiotic stress and stress combination. Plant J 90: 856-867

Conklin PL, Pallanca JE, Last RL, Smirnoff N (1997) L-ascorbic acid metabolism in the ascorbate-deficient Arabidopsis mutant vtcl. Plant Physiol 115: 1277-1285

Cueto M, Hernández-Perera O, Martin R, Bentura ML, Rodrigo J, Lamas S, Golvano MP (1996) Presence of nitric oxide synthase activity in roots and nodules of Lupinus albus. FEBS Lett 398: 159-164

Dalton DA, Russell SA, Hanus FJ, Pascoe GA, Evans HJ (1986) Enzymatic reactions of ascorbate and glutathione that prevent peroxide damage in soybean root nodules. Proc Natl Acad Sci USA 83: 3811-3815

Dalton DA, Post CJ, Langeberg L (1991) Effects of ambient oxygen and of fixed nitrogen on concentrations of glutathione, ascorbate, and associated enzymes in soybean root nodules. Plant Physiol 96: 812-818

Dalton DA, Langeberg L, Treneman NC (1993) Correlations between the ascorbateglutathione pathway and effectiveness in legume root nodules. Physiol Plant 87: 365370

Dalton DA, Joyner SL, Becana M, Iturbe-Ormaetxe I, Chatfield JM (1998) Antioxidant defenses in the peripheral cell layers of legume root nodules. Plant Physiol 116: 3743

Dam S, Dyrlund TF, Ussatjuk A, Jochimsen B, Nielsen K, Goffard N, Ventosa M, Lorentzen A, Gupta V, Andersen SU, Enghild JJ, Ronson CW, Roepstorff P, Stougaard J (2014) Proteome reference maps of the Lotus japonicus nodule and root. Proteomics 14: 230-240

Dowdle J, Ishikawa T, Gatzek S, Rolinski S, Smirnoff N (2007) Two genes in Arabidopsis thaliana encoding GDP-L-galactose phosphorylase are required for ascorbate biosynthesis and seedling viability. Plant J 52: 673-689

Dupont L, Alloing G, Pierre O, El Msehli S, Hopkins J, Hérouart D, Frendo P (2012) The legume root nodule: from symbiotic nitrogen fixation to senescence. In: Nagata T (ed) Senescence, chapter 8. InTech Europe, Rijeka, Croatia. pp 137-168

El Msehli S, Lambert A, Baldacci-Cresp F, Hopkins J, Boncompagni E, Smiti SA, Hérouart D, Frendo P (2011) Crucial role of (homo)glutathione in nitrogen fixation in Medicago truncatula nodules. New Phytol 192: 496-506

Eltayeb AE, Kawano N, Badawi GH, Kaminaka H, Sanekata T, Morishima I, Shibahara T, Inanaga S, Tanaka K (2006) Enhanced tolerance to ozone and drought stresses in 
transgenic tobacco overexpressing dehydroascorbate reductase in cytosol. Physiol Plant 127: 57-65

Eltayeb AE, Kawano N, Badawi GH, Kaminaka H, Sanekata T, Shibahara T, Inanaga S, Tanaka K (2007) Overexpression of monodehydroascorbate reductase in transgenic tobacco confers enhanced tolerance to ozone, salt and polyethylene glycol stresses. Planta 225: 1255-1264

Escuredo PR, Minchin FR, Gogorcena Y, Iturbe-Ormaetxe I, Klucas RV, Becana M (1996) Involvement of activated oxygen in nitrate-induced senescence of pea root nodules. Plant Physiol 110: 1187-1195

Foyer CH, Noctor G (2011) Ascorbate and glutathione: the heart of the redox hub. Plant Physiol 155: 2-18

Gogorcena Y, Iturbe-Ormaetxe I, Escuredo PR, Becana M (1995) Antioxidant defenses against activated oxygen in pea nodules subjected to water stress. Plant Physiol 108: $753-759$

Groten K, Vanacker H, Dutilleul C, Bastian F, Bernard S, Carzaniga R, Foyer CH (2005) The roles of redox processes in pea nodule development and senescence. Plant Cell Environ 28: 1293-1304

Groten K, Dutilleul C, van Heerden PDR, Vanacker H, Bernard S, Finkemeier I, Dietz KJ, Foyer CH (2006) Redox regulation of peroxiredoxin and proteinases by ascorbate and thiols during pea rot nodule senescence. FEBS Lett 580: 1269-1276

Halliwell B (2006) Reactive species and antioxidants. Redox biology is a fundamental theme of aerobic life. Plant Physiol 141: 312-322

Hernández-Jiménez MJ, Lucas MM, de Felipe MR (2002) Antioxidant defence and damage in senescing lupin nodules. Plant Physiol Biochem 40: 645-657

Horchani F, Prevot M, Boscari A, Evangelisti E, Meilhoc E, Bruand C, Raymond P, Boncompagni E, Aschi-Smiti S, Puppo A, Brouquisse R (2011) Both plant and bacterial nitrate reductases contribute to nitric oxide production in Medicago truncatula nitrogen-fixing nodules. Plant Physiol 155: 1023-1036

Huang C, He W, Guo J, Chang X, Su P, Zhang L (2005) Increased sensitivity to salt stress in an ascorbate-deficient Arabidopsis mutant. J Exp Bot 56: 3041-3049

Hunt S, Layzell DB (1993) Gas exchange of legume nodules and the regulation of nitrogenase activity. Ann Rev Plant Physiol Mol Biol 44: 483-511 
Jiménez A, Hernández JA, del Río LA, Sevilla F (1997) Evidence for the presence of the ascorbate-gluathione cycle in mitochondria and peroxisomes of pea leaves. Plant Physiol 114: 275-284

Kerchev PI, Pellny TK, Diaz Vivancos P, Kiddle G, Hedden P, Driscoll S, Vanacker H, Verrier P, Hancock RD, Foyer CH (2011) The transcription factor ABI4 is required for the ascorbic acid-dependent regulation of growth and regulation of jasmonatedependent defense signaling pathways in Arabidopsis. Plant Cell 23: 3319-3334

Li F, Wu Q-Y, Sun Y-L, Wang L-Y, Yang X-H, Meng Q-W (2010) Overexpression of chloroplastic monodehydroascorbate reductase enhanced tolerance to temperature and methyl viologen-mediated oxidative stresses. Physiol Plant 139: 421-434

Lim PO, Kim HJ, Nam HG (2007) Leaf senescence. Annu Rev Plant Biol 58: 115-136

Lorence A, Chevone BI, Mendes P, Nessler CL (2004) myo-Inositol oxygenase offers a possible entry point into plant ascorbate biosynthesis. Plant Physiol 134: 1200-1205

Loscos J, Matamoros MA, Becana M (2008) Ascorbate and homoglutathione metabolism in common bean nodules under stress conditions and during natural senescence. Plant Physiol 146: 1282-1292

Marino D, Andrio E, Danchin EGJ, Oger E, Gucciardo S, Lambert A, Puppo A, Pauly N (2011) A Medicago truncatula NADPH oxidase is involved in symbiotic nodule functioning. New Phytol 189: 580-592

Marx H, Minogue CE, Jayaraman D, Richards AL, Kwiecien NW, Siahpirani AF, Rajasekar S, Maeda J, Garcia K, Del Valle-Echevarria AR, Volkening JD, Westphall MS, Roy S, Sussman MR, Ané JM, Coon JJ (2016) A proteomic atlas of the legume Medicago truncatula and its nitrogen-fixing endosymbiont Sinorhizobium meliloti. Nature Biotech 34: 1198-1205

Matamoros MA, Baird LM, Escuredo PR, Dalton DA, Minchin FR, Iturbe-Ormaetxe I, Rubio MC, Moran JF, Gordon AJ, Becana M (1999) Stress-induced legume root nodule senescence: physiological, biochemical, and structural alterations. Plant Physiol 121: 97-111

Matamoros MA, Loscos J, Coronado MJ, Ramos J, Sato S, Testillano PS, Tabata S, Becana M (2006) Biosynthesis of ascorbic acid in legume root nodules. Plant Physiol 141: $1068-1077$

Matamoros MA, Fernández-García N, Wienkoop S, Loscos J, Saiz A, Becana M (2013) Mitochondria are an early target of oxidative modifications in senescing legume nodules. New Phytol 197: 873-885 
Matamoros MA, Peñuelas M, Kim A, Ihling C, Griesser E, Frolov A, Fedorova M, Hoffmann R, Becana M (2017) Protein carbonylation and glycation in legume nodules. Plant Physiol (submitted)

Meakin GE, Bueno E, Jepson B, Bedmar EJ, Richardson DJ, Delgado MJ (2007) The contribution of bacteroidal nitrate and nitrite reduction to the formation of nitrosylleghemoglobin complexes in soybean root nodules. Microbiology 153: 411419

Meilhoc E, Boscari A, Bruand C, Puppo A, Brouquisse R (2011) Nitric oxide in legume-rhizobium symbiosis. Plant Sci 181: 573-581

Miller G, Suzuki N, Ciftci-Yilmaz S, Mittler R (2010) Reactive oxygen species homeostasis and signaling during drought and salinity stresses. Plant Cell Environ 33: $453-467$

Minchin FR (1997) Regulation of oxygen diffusion in legume nodules. Soil Biol Biochem 29: 881-888

Minchin FR, James EK, Becana M (2008) Oxygen diffusion, production of reactive oxygen and nitrogen species, and antioxidants in legume nodules. In Nitrogen-Fixing Leguminous Symbioses (MJ Dilworth, ed), pp 321-362. Springer

Müller-Moulé P, Havaux M, Niyogi KK (2003) Zeaxanthin deficiency enhances the high light sensitivity of an ascorbate-deficient mutant of Arabidopsis. Plant Physiol 133: $748-760$

Myllylä R, Kuutti-Savolainen E-R, Kivirikko KI (1978) The role of ascorbate in the prolyl hydroxylase reaction. Biochem Biophys Res Comm 83: 441-448

Naya L, Ladrera R, Ramos J, González EM, Arrese-Igor C, Minchin FR, Becana M (2007) The response of carbon metabolism and antioxidant defenses of alfalfa nodules to drought stress and to the subsequent recovery of plants. Plant Physiol 144: 1104-1114

Noctor G, Foyer CH (1998) Ascorbate and glutathione: keeping active oxygen under control. Annu Rev Plant Physiol 49: 249-279

Oldroyd GED (2013) Speak, friend, and enter: signaling systems that promote beneficial symbiotic associations in plants. Nat Rev Microbiol 11: 252-263

Pastori GM, Kiddle G, Antoniw J, Bernard S, Veljovic-Jovanovic S, Verrier PJ, Noctor G, Foyer CH (2003) Leaf vitamin C contents modulate plant defense transcripts and regulate genes that control development through hormone signaling. Plant Cell 15: 939-951 
Pavet V, Olmos E, Kiddle G, Mowla S, Kumar S, Antoniw J, Alvarez ME, Foyer CH (2005) Ascorbic acid deficiency activates cell death and disease resistance responses in Arabidopsis. Plant Physiol 139: 1291-1303

Pisoschi AM, Pop A (2015) The role of antioxidants in the chemistry of oxidative stress: a review. Eur J Med Chem 97: 55-74

Puppo A, Groten K, Bastian F, Carzaniga R, Soussi M, Lucas MM, De Felipe MR, Harrison J, Vanacker H, Foyer CH (2005) Legume nodule senescence: roles for redox and hormone signalling in the orchestration of the natural aging process. New Phytol 165: 683-701

Puppo A, Pauly N, Boscari A, Mandon K, Brouquisse R (2013) Hydrogen peroxide and nitric oxide: key regulators of the legume-rhizobium and mycorrhizal symbioses. Antioxid Redox Signal 18: 2202-2219

Rady MM, Hemida KA (2016) Sequenced application of ascorbate-proline-glutathione improves salt tolerance in maize seedlings. Ecotoxic Environ Safety 133: 252-259

Ross EJH, Kramer SB, Dalton DA (1999) Effectiveness of ascorbate and ascorbate peroxidase in promoting nitrogen fixation in model systems. Phytochem 52: 12031210

Rubio MC, James EK, Clemente MR, Bucciarelli B, Fedorova M, Vance CP, Becana M (2004) Localization of superoxide dismutases and hydrogen peroxide in legume root nodules. Mol Plant Microbe Interact 17: 1294-1305

Sánchez C, Gates AJ, Meakin GE. Uchiumi T, Girard L, Richardson DJ, Bedmar EJ, Delgado MJ (2010) Production of nitric oxide and nitrosylleghemoglobin complexes in soybean nodules in response to flooding. Mol Plant-Microbe Interact 23: 702-711

Santos, R, Hérouart D, Sigaud S, Touati D, Puppo A (2001) Oxidative burst in alfalfaSinorhizobium meliloti symbiotic interaction. Mol Plant Microbe Interact 14: 86-89

Shalata A, Neumann PM (2001) Exogenous ascorbic acid (vitamin C) increases resistance to salt stress and reduces lipid peroxidation. J Exp Bot 52: 2207-2211

Torres-Jerez I, Huertas-Ruz R, Lara-Dampier V, Dalton D, Udvardi M (2017) Enhancing SNF and stress tolerance via over-expression of ascorbate biosynthesis genes. 20th International Nitrogen Fixation Congress. Granada, Spain

Udvardi M, Poole PS (2013) Transport and metabolism in legume-rhizobia symbioses. Annu Rev Plant Biol 64: 781-805

Valpuesta V, Botella MA (2004) Biosynthesis of L-ascorbic acid in plants: new pathways for an old antioxidant. Trends Plant Sci 9: 573-577 
Vasse J, de Billy F, Camut S, Truchet G (1990) Correlation between ultrastructural differentiation of bacteroids and nitrogen fixation in alfalfa nodules. J Bacteriol 172: 4295-4306

Veljovic-Jovanovic SD, Pignocchi C, Noctor G, Foyer CH (2001) Low ascorbic acid in the $v t c-1$ mutant of Arabidopsis is associated with decreased growth and intracellular redistribution of the antioxidant system. Plant Physiol 127: 426-435

Wasternack C, Hause B (2013) Jasmonates: biosynthesis, perception, signal transduction and action in plant stress response, growth and development. An update to the 2007 review in Annals of Botany. Ann Botany 111: 1021-1058

Wheeler GL, Jones MA, Smirnoff N (1998) The biosynthetic pathway of vitamin C in higher plants. Nature 393: 365-369

Witty JF, Minchin FR, Skøt L, Sheehy JE (1986) Nitrogen fixation and oxygen in legume root nodules. Oxford Surv Plant Mol Cell Biol 3: 275-314

Wolucka BA, Goossens A, Inzé D (2005) Methyl jasmonate stimulates the de novo biosynthesis of vitamin C in plant cell suspensions. J. Exp Bot 56: 2527-2538

Xiang C, Oliver DJ (1998) Glutathione metabolic genes coordinately respond to heavy metals and jasmonic acid in Arabidopsis. Plant Cell 10: 1539-1550

Yoshida S, Tamaoki M, Shikano T, Nakajima N, Ogawa D, Ioki M, Aono M, Kubo A, Kamada H, Inoue Y, Saji H (2006) Cytosolic dehydroascorbate reductase is important for ozone tolerance in Arabidopsis thaliana. Plant Cell Physiol 47: 304308

Zabalza A, Gálvez L, Marino D, Royuela M, Arrese-Igor C, González EM (2008) The application of ascorbate or its immediate precursor, galactono-1,4-lactone, does not affect the response of nitrogen-fixing pea nodules to water stress. J Plant Physiol 165: $805-812$

Zechmann B (2011) Subcellular distribution of ascorbate in plants. Plant Signal Behavior 6: 360-363 


\section{Figure Legends}

Figure 1 Comparison of indeterminate and determinate nodules. The figure shows the major structural and biochemical differences between the two types of nodules. In the photographs, note the red color in the fixation (III) zone of the indeterminate nodule and in the infected zone of the determinate nodule, which is due to the high concentration of Lb. Also note the green color in the senescent (IV) zone of the indeterminate nodule, indicative of Lb degradation to biliverdin-like pigments.

Figure 2 Localization of respiratory dehydrogenase activity in nodules. The activity, attributable to electrons leaking from the mitochondrial electron transport chain, is localized in the endodermis and parenchyma region (blue arrow) of alfalfa nodules. NC, nodule cortex; NE, nodule endodermis; NP, nodule parenchyma; INF, infected zone. Bar, $100 \mu \mathrm{m}$. [Dalton et al. 1998; printed with permission from American Society of Plant Biologists].

Figure 3 Localization AsA and APX protein in nodules. (A) Histochemical localization of AsA in alfalfa nodules. The presence of high AsA concentrations in the nodule endodermis is marked by deposition of silver particles precipitated fron $\mathrm{AgNO}_{3}$ (yellow arrows). Abbreviations are as in Figure 2. (B) Negative control for A, in which the tissue was preincubated with buffer at $\mathrm{pH} 9.0$ to oxidize the AsA before exposure to $\mathrm{AgNO}_{3}$. (C) Immunolocalization of APX in alfalfa nodules. Typical section showing Ag particles (APX protein) concentrated in the infected region (blue arrow) and in the nodule endodermis (yellow arrows). Abbreviations are as in Figure 2. (D) Similar to C, except that detection was based on Cy3 fluorescence. Bars, $100 \mu \mathrm{m}$. [Dalton et al. 1998; printed with permission from American Society of Plant Biologists].

Figure 4 In situ hybridization of APX mRNA in nodules. The image shows high levels of mRNA in an infected cell (I) and low levels in an adjacent uninfected (interestitial) cell (U). The label is evident as small bright dots. Other features include numerous bacteroids (nearly continuous bumps in I) and starch grains in U. Bar, $10 \mu \mathrm{m}$. [Dalton et al. 1998; printed with permission from American Society of Plant Biologists]. 
Figure 5 Histochemical localization of (homo)glutathione in nodules. (A) Turquoise blue fluorescence in the parenchyma/inner cortex of a cowpea (Vigna unguiculata) nodule. The fluorescence is emitted by the adduct formed between homoglutathione or glutathione and monochlorobimane, a probe that reacts with the thiol groups of both tripeptides. (B) Negative control treated similarly except for the omission of monochlorobimane. OC, outer cortex; IC, inner cortex; INF infected zone. [Dalton et al. 1998; printed with permission from American Society of Plant Biologists].

Figure 6 Nitrogen-fixing activity (acetylene reduction to ethylene) by nodules from soybean plants receiving AsA by stem infusion. Control: no infusion; IV control, infusion with malate/phosphate buffer only; other treatments with concentration of AsA as shown in malate/phosphate buffer. Day number is days after planting. The stem infusion began on day 18 and was continuous through day 45. [Bashor and Dalton, 1999; printed with permission from John Wiley and Sons]. 
Table I Experimental evidence for the presence of the galactose pathway of AsA biosynthesis and its regulation in legume nodules.

\begin{tabular}{|c|c|c|c|c|}
\hline Gene $^{\mathrm{a}}$ & $\begin{array}{l}\text { Evidence in } \\
\text { nodules }\end{array}$ & Regulation $^{b}$ & Conditions & References \\
\hline$P M M$ & Protein & & & (2) \\
\hline GMP/VTC1 & mRNA & $\mathrm{T}, \mathrm{PT}(\mathrm{P})$ & $\mathrm{Cd}$, aging & $(1)(3)$ \\
\hline$G M E$ & mRNA/protein & $\mathrm{T}, \mathrm{PT}(\mathrm{P}, \mathrm{Ac})$ & $\mathrm{Cd}$, aging & $(1)(2)(3)$ \\
\hline GGP/VTC2 & Protein & $\mathrm{PT}(\mathrm{G})$ & & (4) \\
\hline GalPP & mRNA & $\mathrm{T}$ & Aging & $(1)(2)$ \\
\hline GalDH & mRNA & $\mathrm{T}$ & $\mathrm{Cd}$, aging & (1) \\
\hline GalLDH & mRNA/activity & $\mathrm{T}$ & $\mathrm{Cd}, \mathrm{H}_{2} \mathrm{O}_{2}, \mathrm{JA}$, aging & (1) \\
\hline
\end{tabular}

a Abbreviations: PMI, phosphomannose isomerase; PMM, phosphomannose mutase; GMP, GDP-mannose pyrophosphorylase; GME, GDP-mannose 3,5-epimerase; GGP, GDP-L-galactose phosphorylase; GalPP, L-galactose-1-P phosphatase; GalDH, Lgalactose dehydrogenase.

${ }^{\mathrm{b}} \mathrm{T}$, transcriptional. PT, post-transcriptional: (P) phosphorylation, (Ac) acetylation, $(\mathrm{G})$ glycation.

c (1) Loscos et al. (2008); (2) Dam et al. (2014); (3) Marx et al. (2016); (4) Matamoros et al. (unpublished data). 

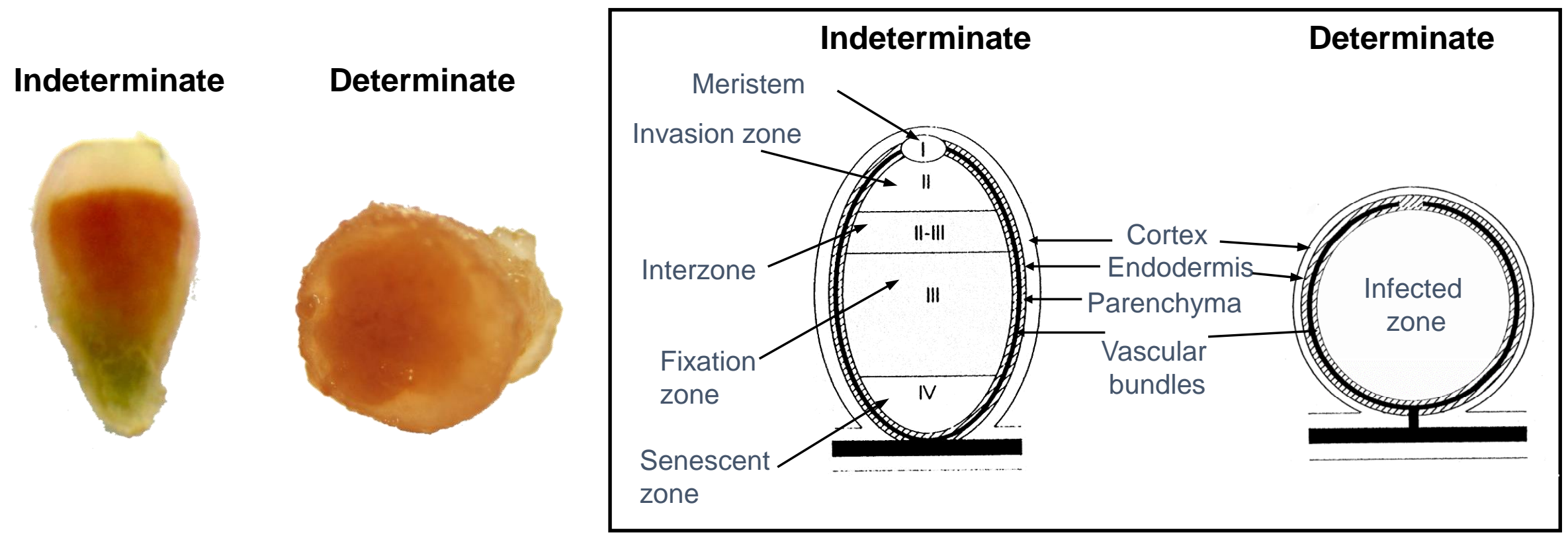

\begin{tabular}{|l|l|l|}
\hline & Indeterminate & Determinate \\
\hline Host plant & Alfalfa, pea, Medicago truncatula & Bean, soybean, Lotus \\
Geographic origin & Temperate & Tropical and subtropical \\
Nodule shape & Elongated & Spherical \\
Initial cell divisions & Inner cortex & Outer cortex \\
Nodule growth & Cell division. Persistent meristem & Cell expansion \\
Flavonoids inducing nod genes & Isoflavones & Flavones, flavonones \\
Export of assimilated nitrogen & Amides & Ureides (Lotus is an exception) \\
\hline
\end{tabular}




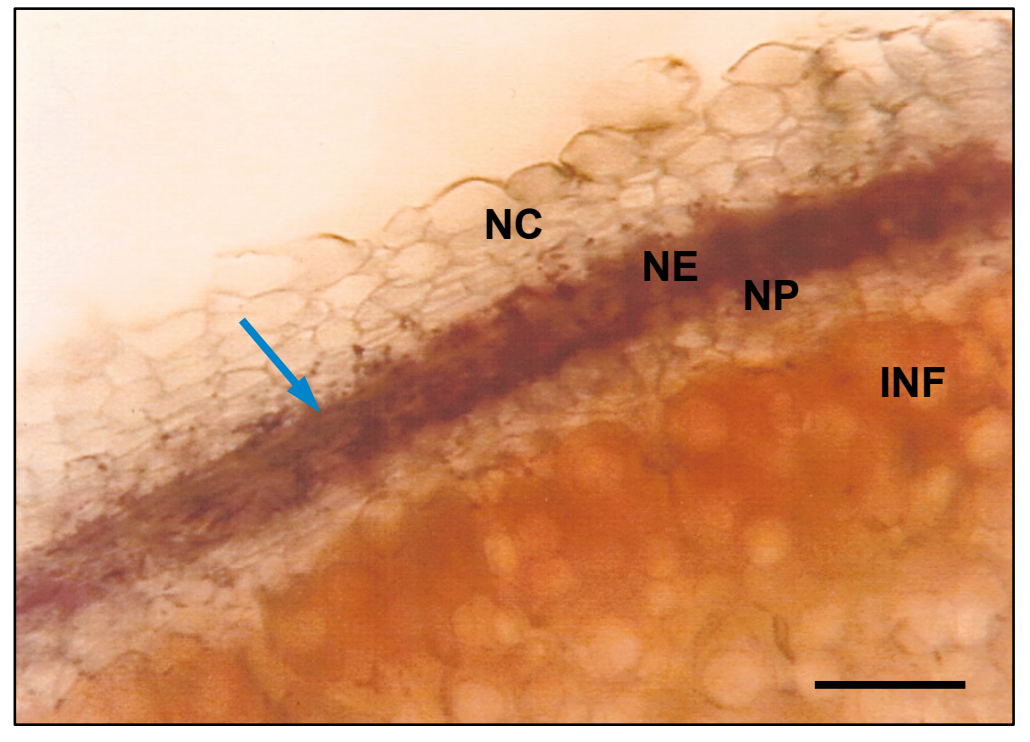




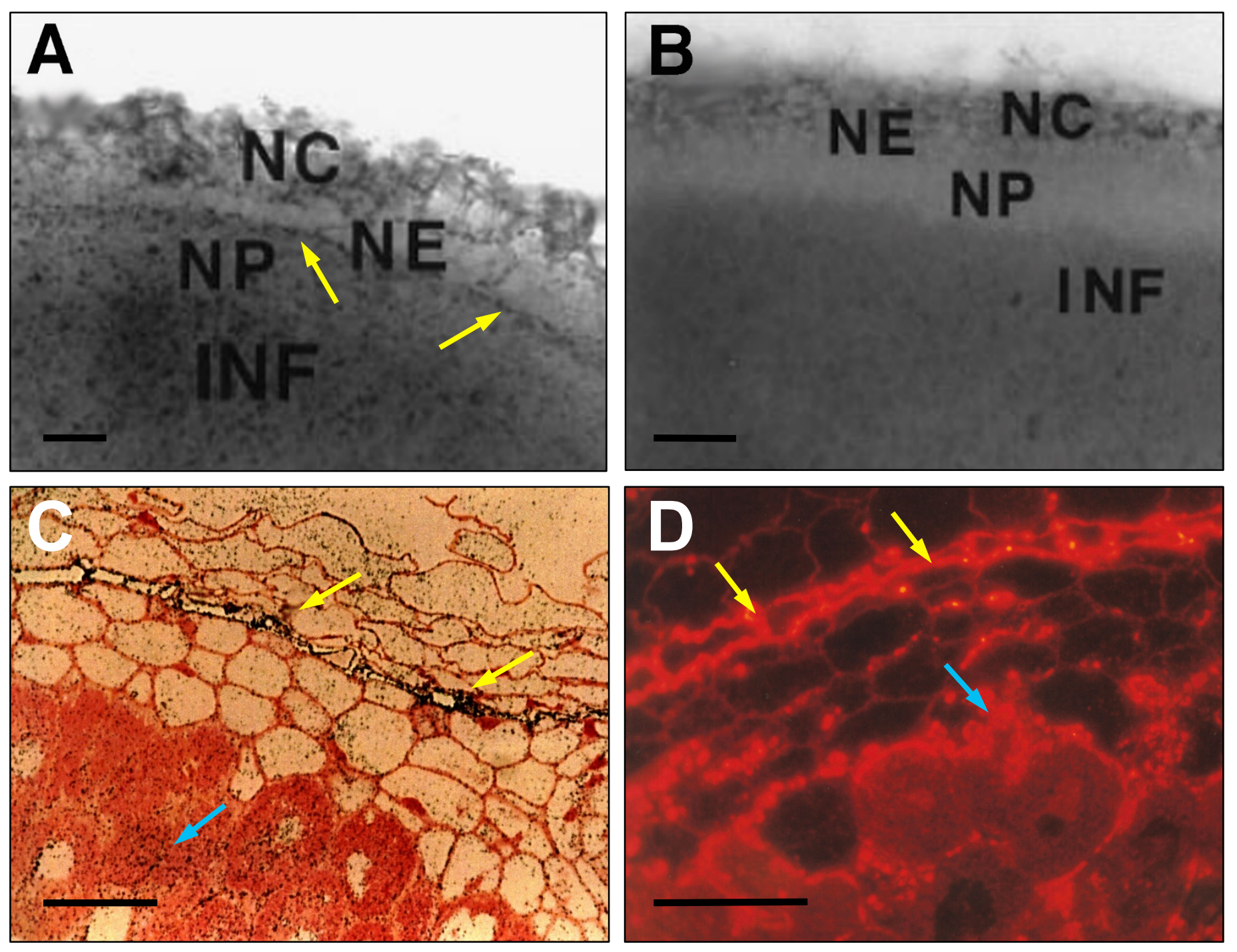




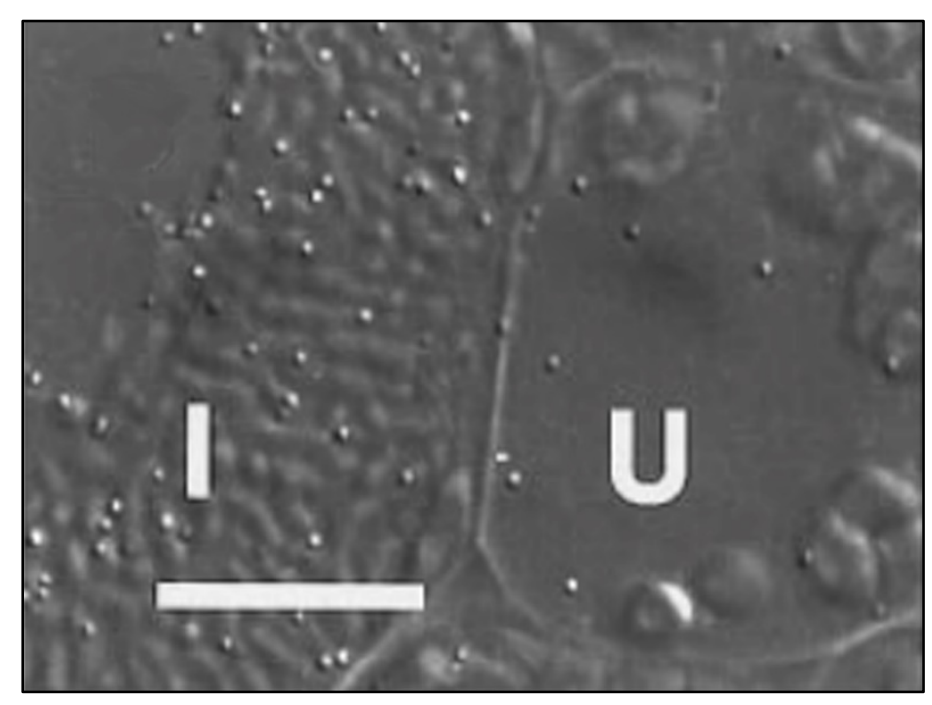




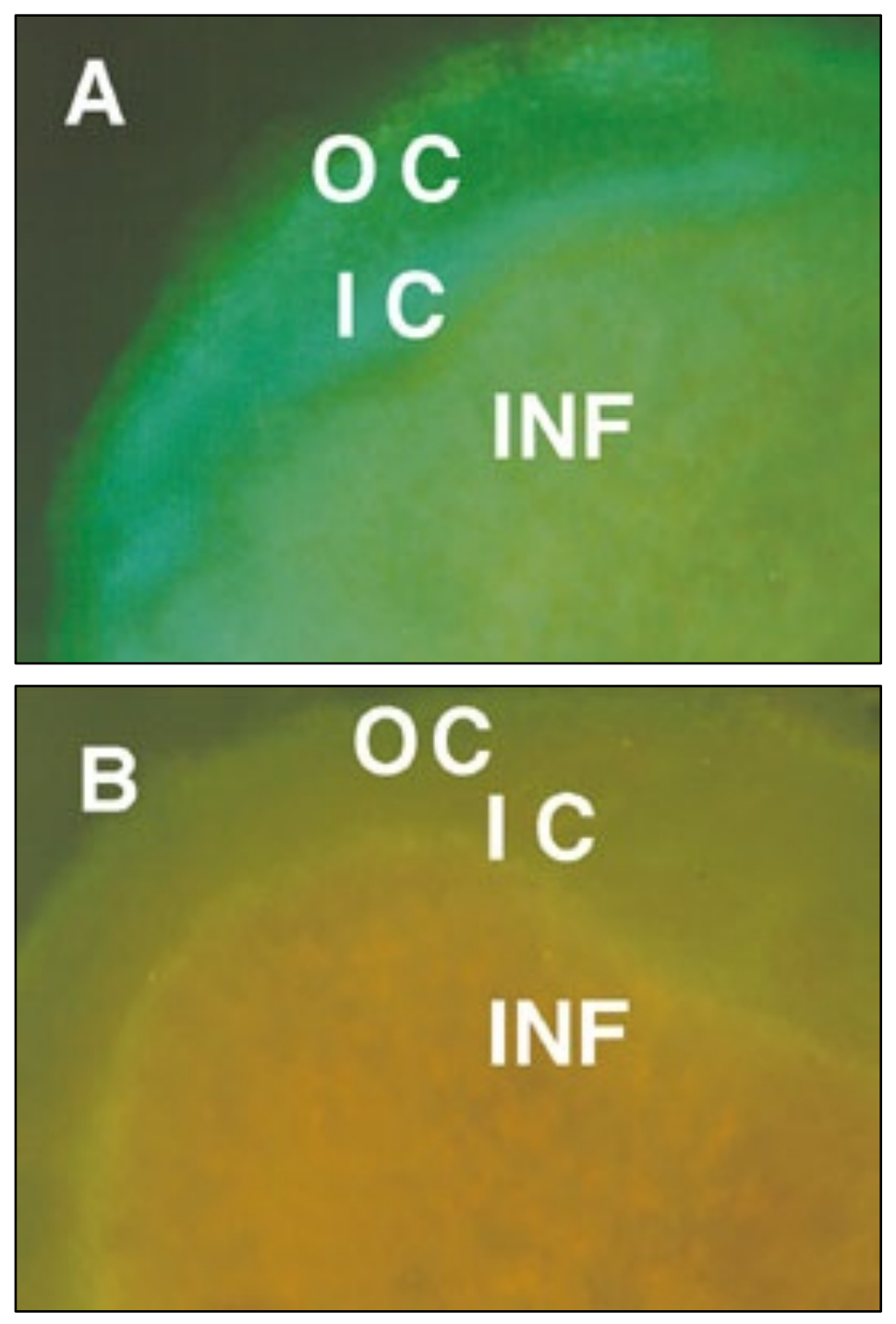




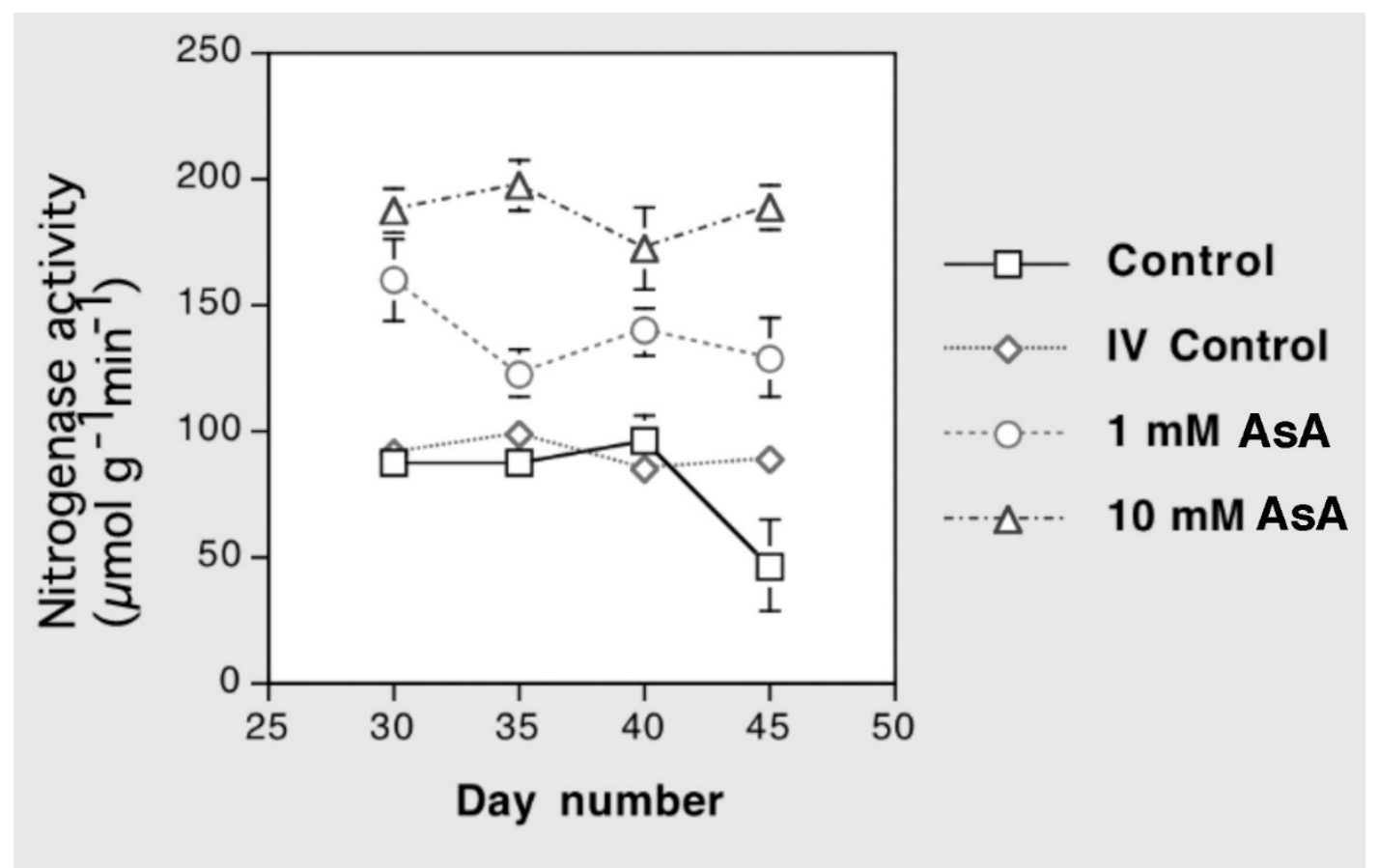

